\title{
O PLANO DE ESTUDO NA ARTICULAÇÃO ENTRE OS TEMPOS E ESPAÇOS DA FORMAÇÃO POR ALTERNÂNCIA
}

\author{
MELO, Érica Ferreira - Universidade Federal de Viçosa \\ Melo.ericaferreira@gmail.com \\ SILVA, Lourdes Helena - Universidade Federal de Viçosa \\ lhsilvaii@gmail.com
}

RESUMO: Nos últimos anos, no âmbito do movimento da Educação do Campo, tem ocorrido uma ampliação dos Centros Familiares de Formação por Alternância (CEFFAs). No desenvolvimento de sua proposta pedagógica, os CEFFAs utilizam diversos instrumentos pedagógicos, visando articular os diferentes tempos e espaços que constituem o processo de formação. Dentre eles, o Plano de Estudo se destaca como instrumento central na proposta de integrar as aprendizagens do jovem no ambiente familiar e no ambiente escolar. Apesar desta centralidade, ainda são poucos os trabalhos que analisam este instrumento da Pedagogia da Alternância. Neste sentido, apesar da expansão da Alternância em nossa sociedade, ainda existem questões que precisam ser respondidas: Em que consiste o PE? Quais suas etapas? Quais processos encontram-se envolvidos na sua execução? Na busca de responder essas questões, o presente trabalho tem como objetivo descrever as etapas do PE no cotidiano de um CEFFA, especificamente na Escola Família Agrícola Paulo Freire, analisando o seu processo de construção no cotidiano da Escola e das famílias, de maneira a identificar limites e possibilidades deste instrumento na formação dos jovens do campo.

Palavras-chave: Plano de Estudo; Pedagogia da Alternância; Instrumentos Pedagógicos da Alternância.

\section{THE PLAN OF STUDY ON RELATIONSHIP BETWEEN THE TIMES AND SPACES OF TRAINING BY ALTERNATION}




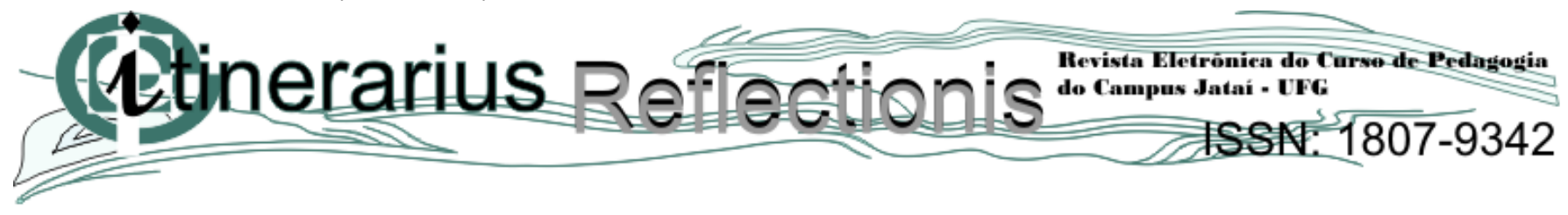

\begin{abstract}
In recent years, under the movement of the Field Education, there has been an expansion of the Family Centers Alternating Educational (CEFFAs). In developing their pedagogical proposal, the CEFFAs use various pedagogical tools in order to articulate the different times and spaces that make up the training process. Among them, the Study Plan stands out as a central instrument in the proposal to integrate the learning of the young man in the family and school environments. Despite this centrality, there are few studies that evaluate this instrument's Pedagogy of Alternation. In this sense, despite the expansion of Alternation in our society, there are still issues that need to be answered: What is the PE? What are your steps? What processes are involved in its implementation? In the search to answer these questions, this paper aims to describe the steps of a PE in everyday CEFFA, specifically the Family Farm School Paulo Freire, analyzing their construction process in everyday school and families, in order to identify limits and possibilities of this instrument in the training of rural youth.
\end{abstract}

Key-words: Study Plan; Pedagogy of Alternation; Instruments Pedagogical Alternation.

\title{
Introdução
}

A Educação do Campo é um movimento nacional, que tem sido construído pelos sujeitos coletivos do campo, na luta contra o processo de exclusão social e em defesa de outra escola, outra educação e de outro projeto de campo. Este projeto sustenta, em sua extensão, uma nova qualidade de vida para os sujeitos que vivem e trabalham no campo; valorizando suas experiências e culturas; fortalece um modelo popular de agricultura, além de procurar recuperar toda a dimensão educativa do trabalho, que possui uma importante dimensão formativa, fundamental para a constituição do humano (ARROYO et al 2009). Trata-se, portanto, de um movimento que visa construir um projeto de Educação do Campo articulado com um projeto de desenvolvimento de campo e de sociedade.

No contexto do movimento da Educação do Campo, diversas experiências educativas têm sido desenvolvidas na atualidade de nossa sociedade, com destaque para os Centros Familiares de Formação por Alternância (CEFFAs), cujas origens foram as experiências francesas das Maisons Familiales Rurales (SILVA, 2003). As primeiras experiências dos CEFFAs no Brasil, segundo Silva (2003), surgiram no final dos anos de 1960, no Estado do Espírito Santo, com a criação da Escola 


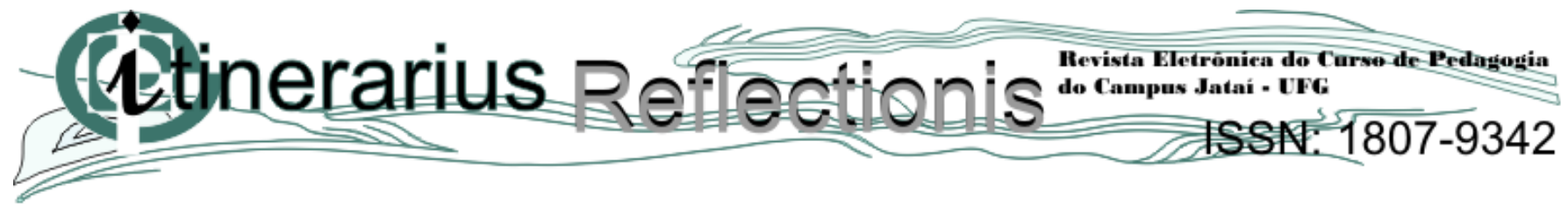

Família Agrícola, em Olivânia, município de Anchieta. A iniciativa de construção da primeira EFA partiu de um Padre, pertencente à Companhia de Jesus que identificou a necessidade de uma escola que fosse capaz de auxiliar nas necessidades do campo naquele estado. Posteriormente, foram organizadas outras EFAS que, gradativamente, foram se multiplicando por todo o Estado do Espírito Santo e, com a consolidação destas experiências educativas em solo Capixaba, elas foram se expandindo para outras regiões brasileiras.

A partir da década de 1980, conforme destaca Silva (2003), teve inicio a emergência de outros Centros de Formação por Alternância, como as Casas Familiares Rurais, inicialmente na região Nordeste e, posteriormente, na região Sul do país, onde encontrou solo fértil para sua permanência e expansão. As EFAs e as CFRs, de acordo com Silva e Queiroz (2007), são, portanto as experiências de formação por alternância mais antigas e significativas na sociedade brasileira, tendo influenciado de maneira direta a implementação de outras experiências de formação por alternância no país. Em 2005, durante o III Encontro Internacional da Pedagogia da Alternância realizado em Foz do Iguaçu - PR, teve início um movimento de articulação das diversas experiências educativas de formação por alternância e de criação da rede denominada Centros Familiares de Formação por Alternância (CEFFAS).

$\mathrm{Na}$ atualidade, os CEFFAs encontram-se presentes em todas as regiões brasileiras, a partir das experiências das Escolas Família Agrícolas (EFAs), Casas Familiares Rurais (CFRs), Escolas Comunitárias Rurais (ECORs), Escolas de Assentamento (EAs), Programa de Formação de Jovens Empresários Rurais (PROJOVEM), Escolas técnicas Estaduais (ETEs), Casas das Famílias Rurais (CDFRs) Centro de Desenvolvimento do Jovem Rural (CEDEJOR) (SILVA e QUEIROZ, 2007).

Cabe destacar também que, no processo de formação dos jovens, os CEFFAs utilizam diversos instrumentos pedagógicos na implementação da Pedagogia da Alternância, que "representa um caminhar permanente entre a vida e a escola. Sai da experiência no encontro de saberes mais teóricos para voltar novamente à experiência, e assim sucessivamente” (GIMONET 2007, p. 29). Busca-se, assim, uma formação orientada por uma dinâmica que, partindo das experiências de vida e trabalho dos jovens, busca avançar no processo de reflexão teórica, processo este orientado para a ressignificação das experiências de vida dos educandos.

No conjunto dos instrumentos utilizados pelos CEFFAs na busca de articulação e integração das aprendizagens no ambiente familiar com as aprendizagens no ambiente escolar, são 


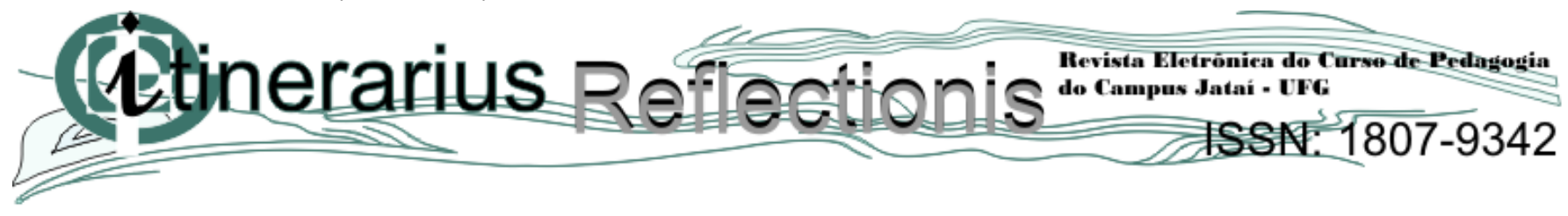

utilizados diversos instrumentos pedagógicos: Plano de Formação, Plano de Estudo, Colocação em Comum, Caderno da Realidade, Caderno Didático, Estágio, Visitas à Comunidade, Visitas e Viagens de Estudo, Intervenções Externas e o Projeto Profissional do Jovem (SILVA, 2009). Dentre os instrumentos de alternância, o Plano de Estudo (PE) se destaca pela sua importância na articulação entre os diferentes tempos e espaços que constituem o processo de formação, como família e escola, prática e teoria, trabalho e educação.

Deste modo, o PE é considerado por autores como Gimonet (2007), Silva (2003), Pereira, (2002), Pettenon e Teixeira (2007), Begnami (2003), Menezes (2003), como sendo o instrumento central da Pedagogia da Alternância. Todavia, apesar desta consideração, ainda são poucos os estudos que se debruçam sobre os processos e praticas de construção do PE nas experiências de formação por alternância em nossa sociedade. Assim, ainda existem questões que precisam ser aprofundadas nos estudos sobre a Pedagogia da Alternância em nossa sociedade: Em que consiste o PE? Quais suas etapas? Quais processos encontram-se envolvidos na sua execução? Na busca de abordar essas questões, o presente trabalho tem como objetivo descrever as etapas do PE no cotidiano de um CEFFA, especificamente na Escola Família Agrícola Paulo Freire-EFAP ${ }^{1}$, analisando o processo de construção deste instrumento no cotidiano da Escola e das famílias ${ }^{2}$, de maneira a compreender os limites e possibilidades deste instrumento na formação dos jovens do campo.

Na realização destes propósitos, realizamos uma caracterização do processo de construção do Plano de Estudos, tanto em uma perspectiva teórica quanto na compreensão e avaliação dos sujeitos envolvidos neste processo- monitores, educandos e famílias da EFAP, de maneira a apresentar elementos que sustentam nossas considerações sobre este instrumento, particularmente seus limites e possibilidades na formação dos jovens do campo.

\section{O PE e sua Dinâmica de Construção na Perspectiva Teórica}

\footnotetext{
${ }^{1}$ A EFAP localiza-se no município de Acaiaca- MG, na Zona da Mata Mineira. De acordo com o último censo do Instituto Brasileiro de Geografia e Estatística (IBGE), Acaiaca conta com uma população de 3.920 habitantes, dentre os quais, em torno de $35 \%$ residem na zona rural.

${ }^{2}$ Este trabalho se origina de uma pesquisa realizada no mestrado cujo o objetivo geral foi analisar as potencialidades educativas do PE, como instrumento da Pedagogia da Alternância em uma EFA, na formação dos jovens do campo.
} 


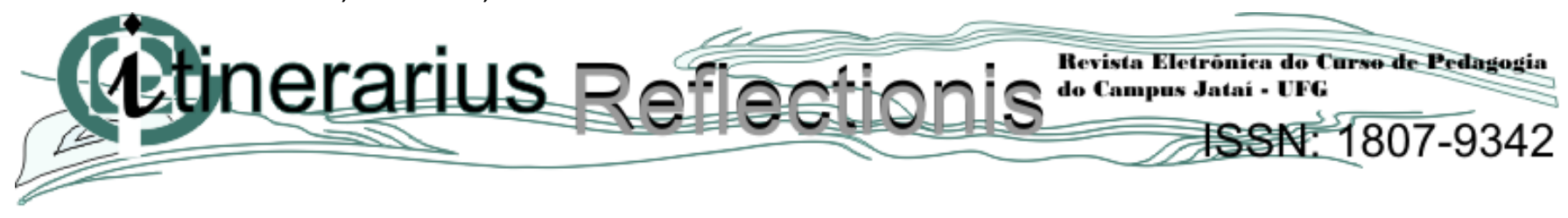

O PE consiste em um roteiro de pesquisa, cujo objetivo é nortear as atividades a serem executadas no processo de formação por alternância, tanto no meio sócio familiar, quanto no meio escolar, envolvendo desde os conteúdos das disciplinas até as intervenções com o meio (GIMONET, 2007). Este instrumento, diferentemente dos planos educacionais tradicionais, visa orientar a elaboração de conteúdos significativos para os educandos. Assim, além da função de nortear as atividades, o PE deve permitir aos educandos indagações sobre o meio em que vivem, assim como a avaliação deles sobre suas ações nesse meio.

Nesta perspectiva Pereira (2002) destaca que o PE deve ser construído em conjunto com os educandos e monitores para ser desenvolvido com as famílias e as comunidades. Essa construção deve estar orientada pela realidade de vida e de trabalho dos jovens, de maneira a permitir e incentivar o diálogo deles com a família. Todavia, segundo o autor, para que isto seja possível, torna-se necessário que os objetivos do PE estejam também orientados pela realidade de vida e de trabalho das famílias.

Pettenon e Teixeira (2007) também consideram que os objetivos do PE devam ser articulados ao contexto e a realidade de vida dos educandos, no conjunto das atividades e experiências vivenciadas no processo de formação. Além dos objetivos estarem articulados com a realidade, os autores também destacam que o PE deve favorecer aos educandos momentos de reflexão e de análises sobre as ações que realizam no seu cotidiano de vida e de trabalho, bem como, assim como ser instrumento de valorização de suas culturas e modos de vida.

$\mathrm{Na}$ realização dos objetivos do PE, autores como Pereira (2002), Gimonet (2007) e Menezes (2003) identificam a existência de diferentes etapas. São etapas que, segundo Menezes (2003, p. 96) precisam ser consideradas como pontos singulares de um holograma, no qual cada ponto contém a totalidade da informação que representam "[...] o Plano de Estudo contém de maneira hologrâmica o todo do qual faz parte e que ao mesmo tempo faz parte dele" (MENEZES, 2003, p. 96). A maioria dos estudos indica que, geralmente, as etapas que compõem o PE são: planejamento, construção, operacionalização, socialização e arquivo. O planejamento do PE envolve a escolha do tema a ser trabalhado e previsto no Plano de Formação do CEFFA que, por sua vez, deve ser relacionado com a realidade de vida e de trabalho dos educandos, tendo por base um diagnóstico da região na qual a escola encontra-se inserida (GIMONET, 2007). Neste processo, a utilização dos temas geradores favorece um levantamento sobre a realidade socioeconômica- 


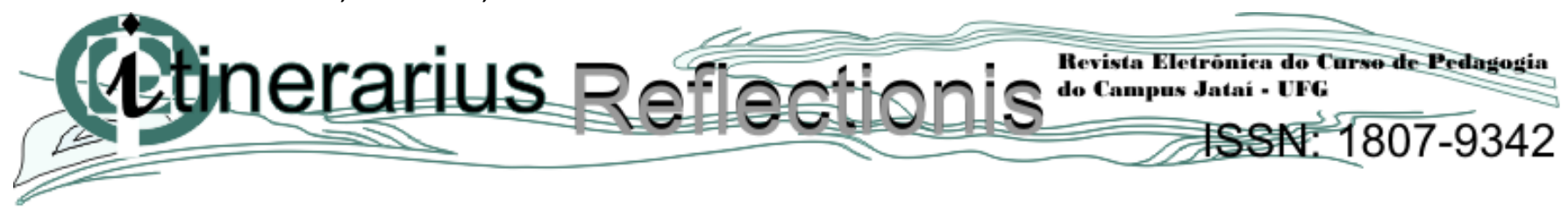

cultural dos educandos e, consequentemente, a possibilidade de um aprofundamento sobre esta realidade a partir dos conteúdos das disciplinas dos CEFFAs (MENEZES, 2003; BEGNAMI, 2003).

Após a escolha do tema, o processo de construção do PE prossegue com um momento de motivação dos educandos sobre a temática escolhida, objetivando, ainda, a elaboração de questões que deverão ser respondidas e/ou pesquisadas durante o período em que os jovens irão permanecer no meio sócio familiar. A elaboração destas questões normalmente envolve duas etapas: a primeira consiste na elaboração do conteúdo, ou seja, do conjunto dos aspectos que serão investigados no âmbito do tema previsto no Plano de Formação. Esta elaboração é realizada em conjunto com os educandos e monitores, numa dinâmica na qual o monitor, por meio de um trabalho de motivação, instiga e favorece a emergência dos aspectos e questionamentos que serão investigados sobre o tema (GIMONET, 2007).

Neste processo de motivação sobre o tema a ser investigado são previstos a utilização de vários recursos didáticos, como roda de conversas, teatros, música, entre outros, visando envolver os educandos na temática de estudo e, em conjunto com eles, identificar os aspectos que serão privilegiados na pesquisa. Ao longo deste processo de motivação também é elaborada uma introdução ao tema que, procedendo às questões do PE, envolve a definição dos objetivos, justificativas e relevância do estudo proposto (MENEZES, 2003).

A segunda etapa da elaboração das questões, segundo Gimonet (2007), consiste na organização e sistematização dos aspectos identificados em um roteiro e/ou documento que, entregue aos educandos, deverá ser realizado no período em que eles permanecerem no meio sócio familiar. Trata-se de uma etapa de sistematização do conjunto dos aspectos à serem investigados, de maneira a atribuir uma estrutura que orienta as observações e possibilite traduzir o conteúdo do tema em um questionamento aberto e instigante.

Após a construção do questionário ou roteiro de questões, e encerrada a etapa de formação no meio escolar, os educandos retornam ao meio sócio familiar, onde devem responder e problematizar as questões do PE (PEREIRA, 2002). Neste momento os educandos irão realizar suas pesquisas, seja em sua propriedade, comunidade, associações e/ou sindicatos, entre outros, podendo contar nesta operacionalização com o auxílio de seus familiares e/ou membros de comunidade, dependendo do local onde deve ser realizada a sua pesquisa. 


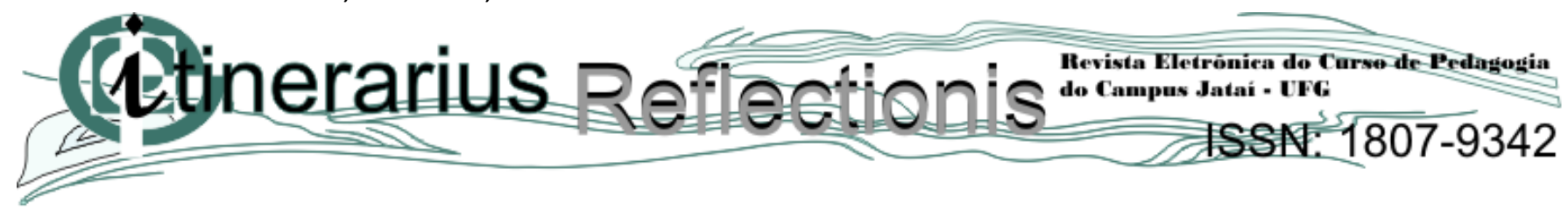

O momento de socialização da pesquisa do PE, denominado de Colocação em Comum, é realizado no retorno do educando ao CEFFA, por meio de debates, discussões e problematizações, onde cada educando apresenta os resultados, observações e análises do seu estudo (PETTENON e TEIXEIRA, 2007). A Colocação em Comum consiste, assim, na socialização dos estudos e reflexões, sendo um: “[...] intercâmbio informal do que cada um viveu de essencial no seu ambiente de vida e depois a atividade mais formal [...]" (GIMONET, 2007, p. 40). Busca-se, desta maneira, articular e colocar em um mesmo patamar de importância as experiências vividas nos dois meios, escola e família, numa perspectiva de reciprocidade, na qual um meio complementa o outro.

Por meio da Colocação em Comum, conforme ressalta Petternon e Teixeira (2007), é possível identificar as convergências e divergências no desenvolvimento do PE de cada educando, assim como possibilita motivar a construção de novos conhecimentos a partir da socialização da pesquisa realizada. Assim, os procedimentos da Colocação em Comum dependem diretamente das possibilidades dos temas de pesquisa, assim como da criatividade dos monitores que, por sua vez, precisam utilizar técnicas e dinâmicas que possibilitem questionamentos e motivação dos educandos para que participem, socializando suas dificuldades e conquistas no desenvolvimento do PE. É importante ressaltar que este momento de compartilhamento e socialização não significa, necessariamente, que o tema do estudo será totalmente explorado de maneira aprofundada. Este aprofundamento será realizado ao longo do período do educando no meio escolar, envolvendo diretamente os conteúdos das disciplinas, das visitas de estudo, entre outras atividades previstas (PETTERNON E TEIXEIRA, 2007; MENEZES, 2003).

Analisando essa dinâmica de operacionalização da Colocação em Comum, Petternon e Teixeira (2007) identificam três grandes fases no desenvolvimento deste instrumento pedagógico da, que são: “[...] descrição dos fatos e processos de realidade; explicação destes em função da necessidade e instrumentalização para retornar a ação" (PETTERNON e TEIXEIRA, 2007, p. 9). Assim, segundo os autores, de inicio são descritos os fatos ocorridos a partir da experiência, da situação vivida dos educandos na realização da pesquisa e/ou estudo do PE; em seguida, eles são estimulados a interpretar os fatos apresentados, delimitando as suas causas, origens e antecedentes, a fim de que os educandos possam ultrapassar o conhecimento ingênuo da realidade, desenvolvendo novas lógicas e/ou concepções que, partindo do concreto, possibilitem proposições de alternativas e/ou soluções para o fenômeno estudado. 


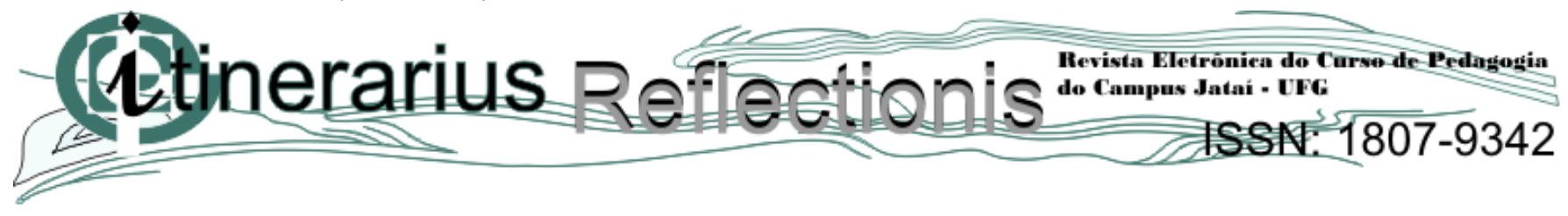

Na sequência, a Colocação em Comum envolve uma sistematização pelos educandos do conjunto das informações e reflexões laboradas a partir do PE e de sua socialização com os colegas, com o registro e arquivo deste processo no Caderno da Realidade (PEREIRA, 2002). Este Caderno, segundo Gimonet (2007), constitui o “[...] instrumento que juntava o conjunto das observações, análises e reflexões que estava sendo construído ao longo da formação" (2007, p. 34). Como um memorial do processo de formação, no Caderno da Realidade fica registrado o conjunto das vivências, experiências e relatos dos educandos que, por sua vez, como instrumento de análise possibilita aos jovens e aos monitores não apenas o registro da trajetória educacional, mas também uma maior compreensão e entendimento da realidade de trabalho e de vida dos estudantes dos CEFFAs.

Em sintese, conforme destacado na produção acadêmica sobre as dinamicas e dispositivos pedagógicos da Alternância nos CEFFAS, o Plano de Estudos assume uma importância e centralidade na articulação dos diferentes tempos e espaços de formação alternada, tanto na perspectiva da relação família-escola, quanto prática-teoria. Além disto, o PE é um dos instrumentos que contribui potencialmente para que a realidade de vida e de trabalho dos educandos seja valorizada e incorporada como parte integrante formação dos jovens por alternância.

\section{A Dinâmica de Construção, Potencialidades e Limites do PE: A Perspectiva dos Monitores,} Educandos e Famílias da EFAP

Em nossa pesquisa sobre o PE no cotidiano da Escola Família Agrícola Paulo Freire (EFAP), os procedimentos técnicos de coleta de dados envolveram a realização de observações e entrevistas à 03 educandos do $3^{\circ}$ ano do Ensino Médio, 03 famílias e 03 monitores. Buscamos identificar, na perspectiva destes sujeitos, como efetivamente o PE tem sido operacionalizado na EFAP, assumindo como referencia as seguintes etapas: planejamento, construção, operacionalização, socialização, arquivo e finalização. O planejamento, compreendido como sendo o momento no qual ocorre a escolha do tema a ser abordado pelo PE; a construção, como o momento de debate e aprofundamento do conhecimento do grupo sobre o tema escolhido e a formulação das questões de estudo; a operacionalização, como a etapa na qual as questões são respondidas no meio sócio familiar; a socialização realizada pela na Colocação em Comum, etapa 


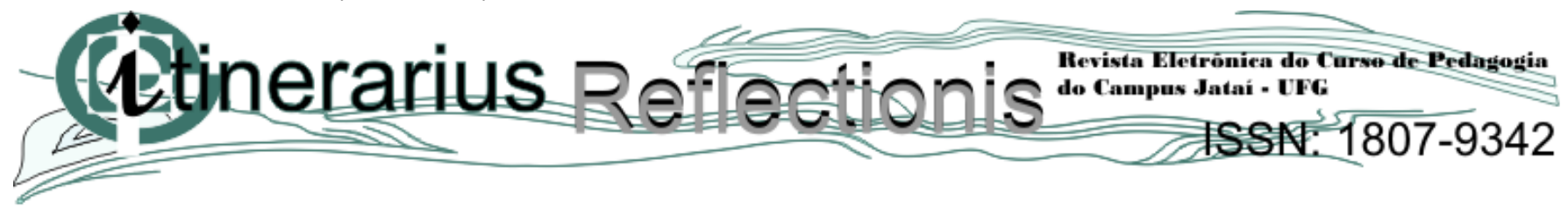

na qual as questões de estudo, informações e reflexões que lhe são decorrentes são sistematizadas coletivamente; e, por último, a etapa de registro, arquivo e finalização das questões por meio da construção de sínteses arquivadas no Caderno da Realidade.

De inicio, é interessante destacar que, questionadas sobre uma definição do o Plano de Estudo, os sujeitos entrevistados revelam diferentes perspectivas: enquanto o conjunto de famílias compreende este instrumento como sendo um "dever de casa", construído no período em que os jovens estão no meio escolar e que deve ser desenvolvido por ele no período no meio sócio familiar; Os educandos revelam uma compreensão sobre o PE associando-o a uma tarefa que, possuindo o formato de um questionário, envolve questões sobre temas variados que devem ser respondidas no meio sócio familiar. Os monitores, por sua vez, destacam a dimensão investigativa do instrumento pedagógico, definindo-o como uma atividade de pesquisa que, possuindo o formato de um roteiro, orienta o processo de levantamento de dados realizado pelo educando no período em que ele esta no meio sócio familiar.

Nesta perspectiva assumida pelos monitores, o PE, enquanto um roteiro de pesquisa se desenvolve por meio de uma sequência que envolve os dois contextos de formação, meio escolar e meio sócio familiar. Assim, primeiramente o roteiro é construído na EFAP, a partir das dúvidas dos educandos sobre o tema de estudo. Após o roteiro construído, os educandos, em suas propriedades e/ou comunidades, elaboram as respostas do roteiro de pesquisa e, posteriormente, de retorno ao meio escolar, apresentam o trabalho realizado. Assim, na perspectiva dos monitores, o PE é assim definido:

Um roteiro para ser desenvolvido na comunidade. Com o objetivo, por exemplo, de tirar as dúvidas que surgiram aqui, esclarecer lá na comunidade ou com a família e depois novamente trazer para esclarecer aqui na escola com os monitores (MONITOR B).

Quanto aos educandos, questionados sobre o PE, definem este instrumento como sendo um questionário, construído no meio escolar, busca enfocar um tema relacionado com a realidade de vida e trabalho dos jovens como suinocultura, cafeicultura, apicultura, entre outros. Segundo os educandos, após a definição/seleção do tema, eles apresentam as suas dúvidas e questionamentos, possibilitando um debate amplo, no qual os monitores também participam. Posteriormente, essas dúvidas são convertidas em questões de estudo que, compondo a estrutura de um questionário, serão respondidas no período de estadia no meio sócio familiar, contando com o auxílio de familiares e/ou 


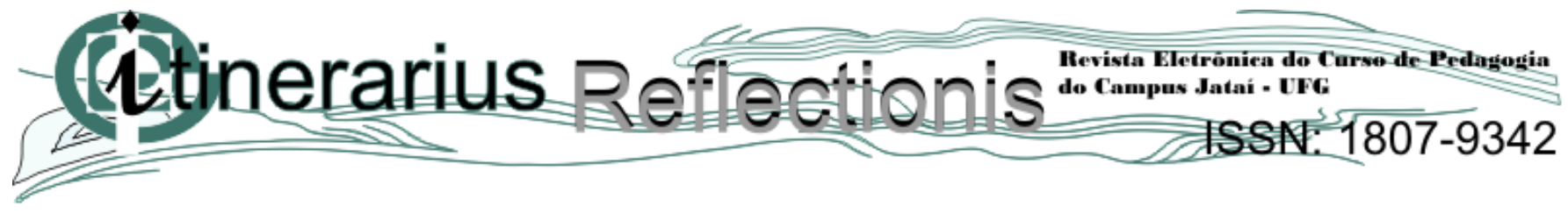

de membros da comunidade. Semelhante a uma entrevista, na aplicação do PE cabe ao educando o papel de entrevistador. Essa perspectiva dos educandos de definição do PE é assim abordada:

O Plano de Estudo é um instrumento da EFAP muito importante para nós estudantes, que serve para tirar dúvida sobre o nosso curso. Nós pegamos um tema, que pode ser bovinocultura, cafeicultura, geralmente são temas que achamos interessantes e gostamos. Logo após, levamos o tema para casa, em forma de questionário, para fazermos a entrevista com alguém e para responder as nossas dúvidas. Depois levamos para a escola novamente (EDUCANDO A).

As famílias, por sua vez, definem o PE como sendo as atividades que os filhos realizam no período em que se encontram no meio sócio familiar, de uma maneira bastante semelhante a um “dever de casa". É importante ressaltar que, inicialmente, as famílias demonstraram dificuldades em responder esta questão, manifestando, ainda, certa insegurança em suas respostas. De uma maneira geral, o Plano de Estudo é compreendido como um conjunto de questões que, a exemplo dos deveres de casa tradicionais, exige com que os jovens busquem respostas e/ou informações para sua realização.

Deve ser o dever de casa, aquele que ele faz aqui e às vezes, sai para fazer. Nessa atividade ele sempre está buscando informação. Eu acho que é isso, umas perguntas que ele tem que responder, fazendo alguma coisa (FAMÍLIA B).

Assim como o sentido e/ou finalidade do Plano de Estudo são compreendidas de maneira diferente, o processo de planejamento, ou escolha do tema, deste instrumento também assume significados diversos. Neste aspecto, para as famílias esta fase acontece por meio de uma reunião entre monitores e educandos, na qual são decididas as atividades que os alunos irão realizar durante o período em que permanecerem no meio sócio familiar. Além disso, na compreensão das famílias, não existe uma distinção nas etapas do PE; planejamento e construção constituem um único e mesmo momento. De maneira diferente, a perspectiva dos monitores e dos educandos revelam que são planejamento e construção são processos que, apesar de relacionados, acontecem de maneira distinta na EFAP.

Assim, para os monitores, o planejamento consiste em um processo de construção coletiva do tema do PE, no qual são utilizados fontes e documentos diversos sobre a Pedagogia da Alternância como subsidio á elaboração do tema. Neste processo, ainda segundo os monitores, os propósitos, interesses e motivação dos educandos aos temas definidos também são fontes de consultas e orientam as etapas a posteriori, conforme destacado pelo monitor A, no relato abaixo: 


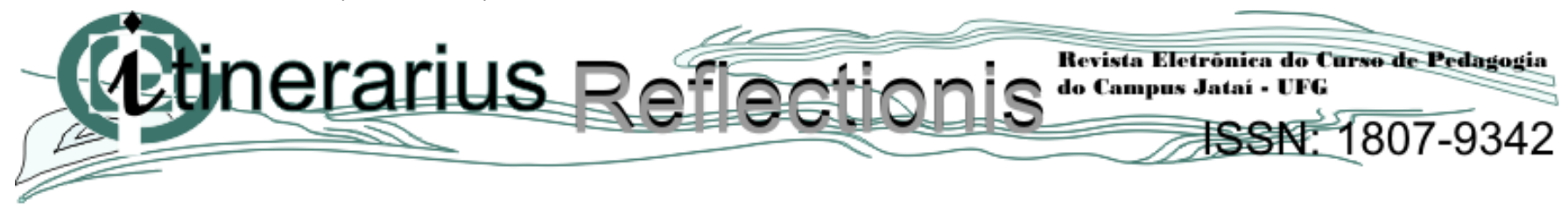

Nós levamos os temas, pesquisamos dentro dos documentos da alternância de outras escolas. Esse ano nós fizemos um levantamento dos propósitos de cada estudante. E trabalhamos os temas que eles queriam. Assim foi válido, esse ano eu acho que nós conseguimos uma participação maior dos próprios estudantes (MONITOR A).

Essa compreensão dos monitores não é compartilhada pelos dos educandos, que compreendem o processo de planejamento PE como sendo centrado nas deliberações apenas dos monitores na escolha dos temas desenvolvidos pelo PE. Em seus relatos indicam que, como um processo centrado nas deliberações do grupo de monitores; quando da apresentação do tema do PE, cabe a eles - mesmo em casos que não consideram a escolha do tema conveniente, apenas aceitar e desenvolver o Plano. Os educandos salientam, ainda, que os momentos no quais os monitores apresentam os temas para o grupo - momentos finais das aulas e/ou do período no meio escolar, nem sempre são momentos oportunos e/ou favoráveis para um posicionamento e sinalização de sugestões pelos educandos, o que acaba favorecendo uma postura de simples aceitação do tema.

Os monitores levam o tema pronto e nós damos a opinião ali. Já aconteceu de nós não gostarmos do tema, mas acabamos aceitando. No final dessa seção mesmo, nós não gostamos tanto do tema, mas, como estava no final da aula e não tínhamos mais tempo, acabamos aceitando (EDUCANDO A).

Diferentemente do processo de planejamento, a construção do PE é considerada pelo conjunto dos entrevistados como sendo uma dinâmica coletiva, envolvendo a participação dos monitores e dos educandos. Organizada na forma de reunião, a construção do PE tem início, na maioria das vezes, com a realização de alguma dinâmica de motivação, envolvendo leituras, mensagens reflexivas, músicas, apresentação de slides, vídeos e outros. A partir do debate do tema escolhido, os educandos apresentam suas dúvidas e questionamentos para que, com o auxílio do monitor, elas sejam transformadas em questões norteadoras do estudo a ser desenvolvido no meio sócio familiar.

Na especificidade da operacionalização do PE no meio sócio familiar, os entrevistados indicam que este é um momento no qual as questões do estudo são respondidas, problematizadas e/ou, dependendo da natureza dos questionamentos, são colocadas em prática. Esta etapa, na maioria das vezes, conta com o envolvimento e participação das famílias, de membros das comunidades e/ou colegas de sala dos educandos, na realização das questões propostas. Este processo de operacionalização do PE é destacado, tanto pelas famílias, quanto pelos educandos, 


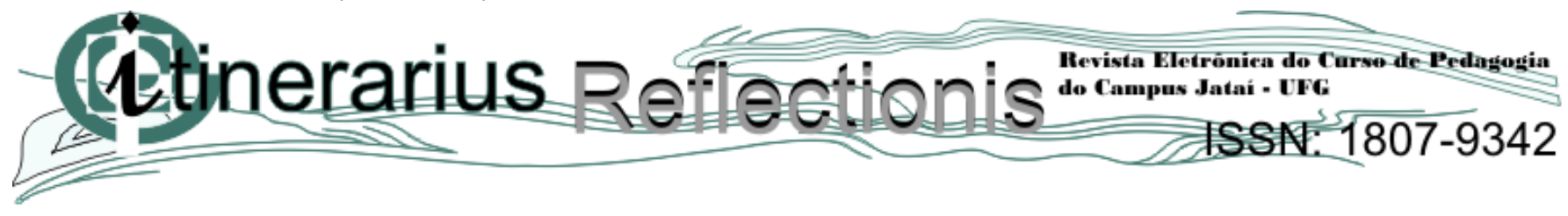

como importante momento de aprendizagens. Todavia, na lógica dos monitores, a perspectiva destacada no processo de operacionalização do PE é a ideia de envolvimento e participação das famílias nas atividades de formação dos jovens. Apesar das dificuldades enfrentadas para o acompanhamento da aplicação do PE no meio sócio familiar, os monitores também ressaltam as dificuldades enfrentadas pelas famílias na compreensão e/ou se interesse no envolvimento nesta etapa do instrumento pedagógico.

Quanto às famílias que participam deste processo de operacionalização do PE, elas se envolvem de diferentes formas: respondendo as questões do questionário, acompanhando os filhos em outras propriedades e/ou em lugares, auxiliando-os em atividades experimentais com animais e/ou na agricultura, entre outros. Assim, pelo envolvimento e inserção nas atividades realizadas pelos jovens, as famílias assumem um papel importante no auxilio ao desenvolvimento do PE.

Eu já ajudei muito, sempre ajudo, respondo várias perguntas, o pai o leva nos lugares. Um dia ele me perguntou como que fazia sabão, perguntou sobre cultura popular, um monte de coisas. Nós sempre ajudamos e se precisar eu vou com ele em outro lugar. Eu sempre estou participando (FAMíLIA A).

Na sequência das atividades do Plano de Estudo, por ocasião do retorno ao meio escolar, tem início a fase de socialização do PE, denominada pelo conjunto dos entrevistados como Colocação em Comum. De uma maneira geral, a Colocação em Comum é compreendida como sendo um momento de apresentação pelos educandos, para os colegas e monitores, dos resultados das pesquisas e/ou estudos realizados no período em que esteve no meio sócio familiar. Na avaliação dos monitores e educandos, é um momento muito importante, no qual eles têm a oportunidade de conhecerem as diferentes realidades de vida e de trabalho dos jovens, assim como as estratégias utilizadas pelas famílias na produção agrícola e pecuária. Além disto, semelhante ao processo de construção do PE, é um momento conduzido e mediado diretamente pelos próprios educandos. A Colocação em Comum é, assim, compreendida como sendo uma dinâmica de socialização, de comparação das realidades e da diversidade dos modos de vida, trabalho e cultura dos educandos da EFAP:

Aqui na EFA Paulo Freire e acho que em outras EFAs mineiras, esse momento é chamado de Colocação em Comum. É justamente esse momento de socializar, de pegar os mais diversos PEs, os PEs que foram feitos nas diferentes comunidades pelos respectivos alunos e observar, quais são os consensos e quais são as grandes diferenças, quais são as singularidades? (MONITOR C). 


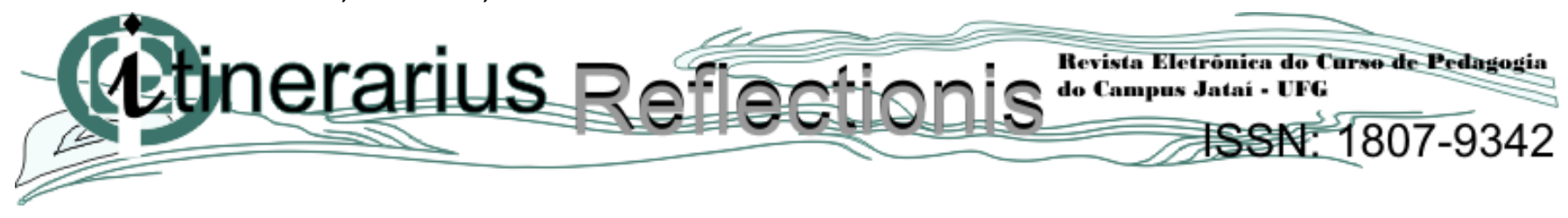

A etapa seguinte, de finalização do PE, é definida como sendo o arquivamento das sínteses construídas na Pasta da Realidade. Os entrevistados referem-se à dinâmica de sistematização, na qual os educandos a partir de uma síntese individual sobre a sua compreensão acerca do tema do PE, construída ainda no período em que estão no meio sócio familiar, irão elaboram, posteriormente no meio escolar e de maneira coletiva, uma síntese sobre a compreensão do grupo. Ao final desta elaboração, cada grupo elege um relator para confecção de uma síntese geral sobre a compreensão do tema do PE. Estas sínteses - individual, grupal e geral, são anexadas na Pasta de Realidade dos jovens, juntamente com ilustrações, mensagens, músicas, enfim os diversos recursos utilizados para ilustrar a compreensão dos educandos sobre o tema desenvolvido pelo PE.

E como estes sujeitos envolvidos na sua realização na EFAP avaliam o Plano de estudos? Especificamente, quais os seus pontos fortes, fragilidades e aspectos que podem ser melhorados? Estes foram outros aspectos que foram questionados aos monitores, educandos e famílias.

As famílias, quando solicitadas a emitirem uma avaliação sobre os aspectos positivos e/ou pontos fortes do PE na especificidade de sua realização no meio escolar, tiveram muitas dificuldades em responder, tanto pela falta de informações sobre este processo, quanto pelo fato de que uma maioria delas não conhecia in loco a Escola Família Agrícola Paulo Freire. Já os monitores destacam como aspectos positivos o envolvimento dos educandos no planejamento do PE e o potencial da interdisciplinaridade do instrumento, que favorece com que as disciplinas sejam organizadas e articuladas em torno de um determinado tema. Os educandos, por sua vez, ressaltam como ponto forte, o momento da Colocação em Comum e a possibilidade que oferece para um contato com outras realidades de vida e trabalho dos colegas.

Quanto aos pontos fracos do PE no meio escolar, os monitores destacam a falta de compreensão de alguns envolvidos no processo de formação, sobre a centralidade do PE na articulação dos diferentes tempos e espaços da formação alternada, favorecendo a falta de um maior envolvimento e comprometimento de monitores e educandos. Os educandos, por sua vez, revelam como sendo uma das maiores fragilidades o processo de desenvolvimento do PE no meio escolar, especificamente as dinâmicas dos momentos de construção do instrumento pedagógico que, segundo eles, nem sempre são bem planejadas. Outro aspecto destacado refere-se à escolha dos temas dos PEs, que em seu planejamento não é realizado de maneira coletiva. Esta é uma perspectiva que converge com a avaliação dos monitores, de que os educandos nem sempre 


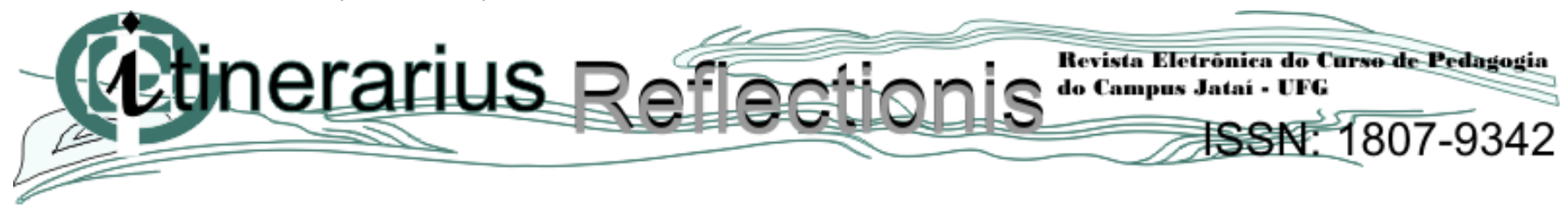

participam do processo de planejamento do $\mathrm{PE}$ e, por isso, acabam por não se envolverem na escolha dos temas.

Em relação às sugestões de melhoria da utilização do PE no meio escolar, os monitores ressaltam a necessidade que o instrumento seja melhor compreendido como sendo um instrumento central na articulação dos tempos e espaços do meio escolar e sócio familiar, portanto, vital no processo de formação por alternância. Os educandos, por sua vez, sugerem que o PE seja desenvolvido de maneira a ser melhor potencializado, destacando que sua melhor e maior articulação com outros instrumentos pedagógicos da alternância, a exemplo das Visitas e Viagens de Estudo e das Intervenções Externas.

Quanto aos pontos fortes, fracos e as sugestões do PE no meio sócio familiar, os monitores indicam a interação entre a família e os educandos na aplicação do PE e o diálogo que o instrumento possibilita com a realidade de vida e de trabalho dos jovens como sendo os pontos fortes. Já as famílias e os educandos são convergentes na opinião de que o aspecto positivo do PE é o de que ele favorece aprendizagens diversas, possibilitando a ampliação dos conhecimentos e das compreensões sobre os temas desenvolvidos.

Quanto aos pontos fracos do PE no meio sócio familiar, os monitores revelam a falta de compreensão de algumas famílias da centralidade do Plano de Estudo, gerando a falta de um envolvimento na operacionalização do instrumento. Os educandos, por sua vez, identificam as dificuldades de aplicação do PE devido tanto ao fato da escolha de tema distantes e sem relação com suas realidades de vida e de trabalho, quanto pela falta de um acompanhamento dos monitores neste processo de operacionalização do Plano de Estudo no meio sócio familiar.

Assim, enquanto os educandos e as famílias apresentam como sugestão de melhoria na efetivação do PE o acompanhamento dos monitores no meio sócio familiar durante a operacionalização do PE; os monitores, por sua vez, sugerem que as famílias compreendam melhor e, consequentemente, tenham um maior envolvimento com o desenvolvimento dos Planos de Estudos.

\section{Considerações Finais}

Analisando o conjunto das percepções dos sujeitos envolvidos no desenvolvimento do PE na Escola Família Agrícola Paulo Freire, identificamos a presença de algumas limitações e 


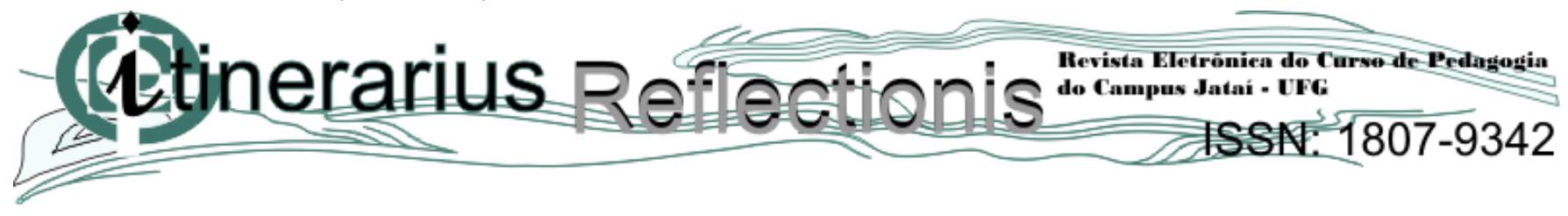

contradições no desenvolvimento do PE enquanto um instrumento articulador dos diferentes tempos e espaços do processo de formação por alternância. Uma delas é a escolha do tema do Plano de Estudo apenas centrada no envolvimento e participação dos monitores. Entre outros aspectos, esse processo nega os princípios propostos pelos CEFFAs, limitando a participação dos educandos e favorecendo com que a realidade de vida e de trabalho dos jovens não seja o ponto de partida da formação. Neste aspecto, cabe destacar, ainda, que a maioria dos monitores não conhece a realidade da propriedade e/ou da comunidade dos estudantes da EFAP, na medida em que não tem as condições necessárias para a realização de visitas aos jovens, acompanhando sua permanência no meio sócio familiar. Essa ausência das visitas dos monitores às propriedades e/ou comunidades dos educandos também foi destacada como outra limitação do PE no processo de articulação dos meios sócio familiar e escolar. Obviamente essa ausência não é uma opção dos monitores, sendo muito mais uma limitação decorrente da falta de recursos financeiros e de infraestrutura da referida instituição de formação por alternância.

Outra limitação identificada é a dificuldade dos monitores em ampliar os recursos do PE enquanto instrumento pedagógico da alternância. Neste aspecto, ele necessita ser melhor potencializado; com o aprofundamento do tema de estudo a partir dos conteúdos das disciplinas e/ou com sua articulação com outros instrumentos da Pedagogia da Alternância, como as Intervenções Externas, Visitas e Viagens de Estudo, entre outros.

Estas são algumas fragilidades e limites que revelam um desencontro entre a proposição teórica do PE e a realidade de sua implantação na realidade e no cotidiano de um CEFFA, especificamente no contexto da Escola Família Paulo Freire.

A despeito de tais limitações, identificamos indícios do PE favorecer praticas de interação, sobretudo no contexto familiar, com o envolvimento, participação e auxilio dos pais no processo de operacionalização do Plano de Estudos, estimulando o diálogo e trocas diversas com os educandos. Outro aspecto que merece ser destacado é o potencial do PE na EFAP, como um instrumento que tem proporcionado, mesmo com limitações, uma articulação entre a formação escolar e o mundo do trabalho dos jovens educandos, suas formas de produção agrícola e pecuária, enfim, com a realidade da agricultura camponesa.

Por fim, cabe reiterar a compreensão de que, apesar do PE constitui um instrumento central nos CEFFAs, com forte potencial para viabilizar o dialogo e a articulação entre os diferentes 


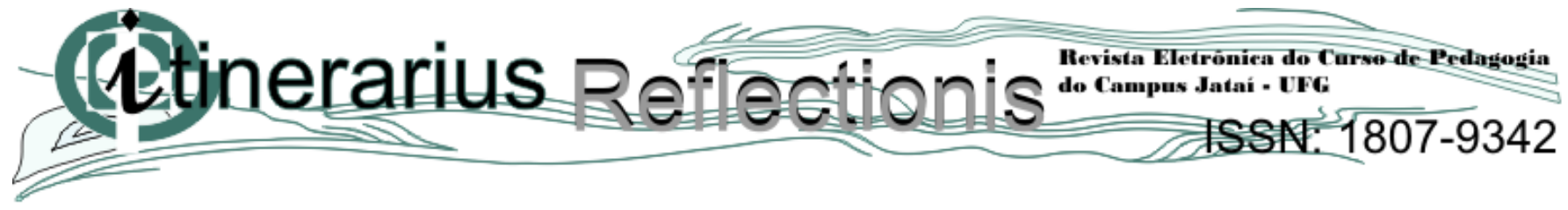

espaços e tempos da formação, este potencial educativo não tem sido totalmente utilizado. Temos, assim, um descompasso entre as proposições teóricas e a prática que vem sendo construída no cotidiano das Escolas Famílias que, por sua vez, também revelam limitações e dificuldades diversas, indo da simples compreensão dos envolvidos sobre o papel do Plano de Estudos na Pedagogia da Alternância, até dimensões mais complexas relacionadas à estrutura, organização e projeto dos CEFFAs brasileiros.

Referências Bibliográficas

ARroYo, Miguel; CALDART, Roseli Salete; MOLINA, Mônica Castagna (Org.). Por Uma Educação do Campo. $4^{\mathrm{a}}$ ed. Petrópolis, RJ: Vozes, 2009. 214 p

BEGNAMI, João Batista. Formação pedagógica de monitores das escolas famílias agrícolas e alternâncias: Um Estudo Intensivo dos Processos Formativos de cinco Monitores. 2003. 319 f. Dissertação (Mestrado internacional em ciências da Educação). Universidade Nova de LisboaPortugal - Universidade François Rabelais de Tours-França, 2003.

GIMONET, Jean Claude. Praticar e compreender a pedagogia da alternância dos CEFFAs. Trad: Thierryde Burghgrave. Petrópolis, RJ: Vozes, 2007. 168p.

MENEZES, Raquel Reis. Novo paradigma educativo e práticas pedagógicas das EFAS: análise de planos de estudos inovadores em relação aos sete saberes da educação do futuro do Morin. 2003. 187 f. Dissertação (Mestrado internacional em ciências da Educação). Universidade Nova de Lisboa-Portugal - Universidade François Rabelais de Tours-França, 2003.

PEREIRA, Cenira Peres da Silva. Plano de Estudo: Instrumento pedagógico utilizado na Pedagogia da Alternância. 2002. 36 f. Trabalho de Conclusão de Curso (TCC). Universidade Federal de Viçosa, MG, 2002.

PETTENON, Cristina. Vial; TEIXEIRA, Edval. Sebastião. A colocação em comum como instrumento da pedagogia da alternância: um estudo com monitores e jovens em CFRS do sul do Brasil. In: I Seminário Sobre Educação e Desenvolvimento: Pedagogia da Alternância e Desenvolvimento Sustentável, 2007, Pato Branco. Anais... Pato Branco, PR: UTFPR, 2007, p. 0116. 
Primeiro semestre 2014, volume 1, número 16.

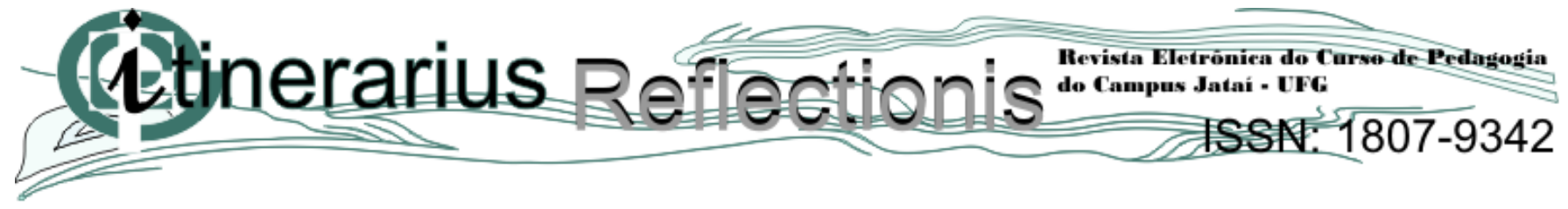

SILVA, Lourdes Helena. As experiências de formação de jovens do campo: alternância ou alternâncias? Viçosa: UFV, 2003. p. 266.

Centros familiares de formação por alternância: avanços e perspectivas na construção da educação do campo. Cadernos de Pesquisa Pensamento Educacional, v. 8, p.270-290, jul./dez. 2009.

SILVA, Lourdes Helena; QUEIROZ, João Batista Pereira de. Alternância: concepções e práticas no Brasil. In: Lucia Helena Correa Lenzi; Denise Cord. (Org.). Formação de educadores (as) em EJA no campo: compartilhando saberes. Florianópolis: NUP/CED/UFSC, 2007, p. 94-110. 